\title{
ANALISIS PREFERENSI KONSUMEN TERHADAP KOPI LOKAL DI KOTA JAMBI
}

\section{CONSUMER'S PREFERENCES OF LOCAL COFFE AT JAMBI CITY}

\author{
Mulyani \\ Program Studi Agribisnis Fakultas Pertanian Universitas Batanghari \\ Jalan Slamet Riyadi No.1, Sungai Putri, Danau Teluk, Kota Jambi, Jambi 36122, Indonesia \\ mulyani@unbari.ac.id
}

\begin{abstract}
ABSTRAK
Tujuan dalam penelitian ini adalah menganalisis preferensi konsumen yakni masyarakat kota Jambi terhadap kopi lokal dan menganalisis hubungan usia terhadap preferensi masyarakat kota Jambi dalam mengkonsumsi kopi lokal. Adapun hipotesis dalam penelitian ini adalah terdapat hubungan antara usia konsumen kopi dengan preferensi dalam mengkonsumsi kopi lokal Jambi.Penelitian ini dilakukan di Kota Jambi dengan mengumpulkan data primer dan sekunder. Penelitian ini dilaksanakan pada bulan Februari sampai Juni 2020. Data yang digunakan adalah data cross section. Data konsumen dikumpulkan dari 3 kedai kopi yang terdapat di Kota Jambi yakni Hello Sapa, Camp Coffee, dan Kopi Juaro. Penarikan sample dilakukan dengan metode simpel random sampling. Penghitungan sampel dengan rumus Slovin. Hasil penelitian menunjukkan bahwa Mayoritas konsumen kopi memilih kopi lokal dibandingkan kopi non lokal dan Hubungan usia konsumen dengan preferensi konsumsi kopi adalah tidak signifikan.
\end{abstract}

Kata kunci: Kopi Lokal, Preferensi, usia konsumen

\begin{abstract}
The aim of this researchis to analyze consumer preferences of Jambi city consuming local coffee and to analyze the relationship between age and preferences of the people of Jambi city in consuming local coffee. The hypothesis in this study is that there is a relationship between the age of consumers and preferences in consuming local Jambi coffee. This research was conducted in Jambi City by collecting primary and secondary data. This research conducted from February to June 2020. The data used is cross section data. Consumer data was collected from 3 coffee shops in Jambi City, namely Hello Sapa, Camp Coffee, and Juaro Coffee. The sampling method was simple random sampling. Sample calculation using the Slovin formula. The results showed that the majority of coffee consumers prefer local coffee than non-local coffee and the relationship between consumer age and coffee consumption preference is not significant.
\end{abstract}

Keywords: Local Coffee, Preference, Age of Consumer 


\section{PENDAHULUAN}

Kopi merupakan salah satu komoditi unggulan perkebunan Provinsi Jambi dengan luas $25.847 \mathrm{Ha}$ berupa perkebunan rakyat (Dinas Perkebunan Provinsi Jambi, 2019). Salah satu kebijakan perkebunan di Provinsi Jambi adalah pengembangan kopi, hal ini dikarenakan peluang sisi permintaan kopi yang cukup prospektif di pasar global dimana terjadi peningkatan permintaan kopi di pasar global. Ekspor kopi juga mampu berkontribusi terhadap ekonomi Provinsi Jambi. Pada Triwulan 1 Tahun 2019 ekonomi tumbuh 4,73\% di Provinsi Jambi dimana terjadi peningkatan kinerja ekspor kopi dan pinang yang mampu menopang pertumbuhan ekonomi Provinsi Jambi (Bank Indonesia, 2019). Areal pengembangan komoditi kopi di Provinsi Jambi dibagi menjadi 2 zona yakni zona barat dan zona timur. Untuk zona barat berada di Kota Sungai Penuh, Kabupaten Kerinci, dan Kabupaten Merangin. Sedangkan zona timur berada di Kabupaten Tanjung Jabung Barat. Strategi pengembangan komoditi kopi di Provinsi Jambi di Fokuskan pada perluasan luas areal tanam, ekspor kopi mentah, dan industri pengolahan kopi.

Kopi Liberika Tungkal Komposit dibudidayakan di zona timur tepatnya di Kabupaten Tanjung Jabung Barat pada ketinggian 0-500 mdpl. Kopi ini dikembangkan di 3 kecamatan yakni kecamatan Kuala Betara, Bram Itam, Senyerang, dan Pengabuan dengan luas tanam 2.710 Ha. Sebagai jenis kopi yang tergolong baru (tahun 2012 didaftarkan pada Direktorat Jenderal Hak Kekayaan Intlektual Kementerian Hukum dan HAM untuk memperoleh sertifikat Indikasi Geografis) maka perlu diketahui bagaimana Preferensi masyarakat Jambi dalam mengkonsumsi kopi lokal (Kopi Kerici, Kopi Muara Madras, dan Liberika Tungkal Komposit). Oleh karena itu akan dilakuakan penelitian berjudul "Analisis Preferensi Masyarakat Kota Jambi Terhadap Kopi Lokal".
Batasan masalah yang akan diteliti adalah bagaimana preferensi masyarakat kota Jambi dalam mengkonsumsi kopi lokal (Kopi Kerinci, Kopi Muara Madras, dan Liberika Tungkal Komposit).

Asumsi dalam penelitian ini adanya perbedaan preferensi masyarakat Kota Jambi terhadap mengkonsumsi Kopi Lokal. Hal ini karena ada banyak jenis kopi yang beredar di Kota Jambi baik kopi lokal maupun kopi non lokal.

Adapun tujuan dalam penelitian ini adalah:

- Menganalisis preferensi konsumen yakni masyarakat kota Jambi terhadap kopi lokal

- Menganalisis hubungan usia terhadap preferensi masyarakat kota Jambi dalam mengkonsumsi kopi lokal.

Kopi Lokal merupakan salah satu komoditi unggulan sektor perkebunan yang sedang di tingkatkan produksinya oleh pemerintah Jambi sehingga produksinya mengalami peningkatan. Peningkatan produksi ini idealnya diikuti dengan peningkatan konsumsi kopi Lokal. Akan tetapi dengan rasanya yang khas serta agak berbeda dengan kopi yang lain maka penting untuk diteliti bagaimana preferensi konsumen dalam hal ini masyarakat Kota Jambi terhadap Kopi Lokal ini. Adapun hipotesis dalam penelitian ini adalah terdapat hubungan anatara usia konsumen kopi dengan preferensi dalam mengkonsumsi kopi lokal.

\section{METODE PENELITIAN}

Penelitian ini dilakukan di Kota Jambi dimana data yang digunakan adalah data Primer dengan menggunakan kuisioner dan data sekunder yang dikumpulkan dari instansi - instansi terkait yakni dinas perkebunan Provinsi Jambi, Badan Pusat Statistik Provinsi Jambi, dinas Perindustrian dan Perdagangan Provinsi Jambi, dan instansi terkait lainnya. Data yang dukumpulkan adalah data cross section. Pemilihan lokasi dalam penelitian ini adalah 
purpossive dengan pertimbangan bahwa kota Jambi merupakan ibu kota Provinsi Jambi dengan aktifitas perdagangan yang kompleks dan jumlah penduduk yang banyak.

Penelitian ini dilakukan di Kota Jambi dengan mengumpulkan data primer dan sekunder. Penelitian ini akan dilaksanakan pada bulan Februari sampai Juni 2020. Adapun data yang dikumpulkan pada penelitian ini adalah:

1. Identitas konsumen yang mengkonsumsi kopi di Kota Jambi

2. Preferensi masyarakat Kota Jambi terhadap Kopi Lokal Jambi

Data yang dikumpulkan adalah data Primer menggunalan kuisioner dan sekunder yang didapat dari instansi - instansi yang terkait dengan penelitian ini. Data yang digunakan adalah data cross section. Data konsumen dikumpulkan dari 3 kedai kopi yang terdapat di Kota Jambi yakni Hello Sapa, Camp Coffee, dan Kopi Juaro. Pemilihan ketiga kedai kopi ini dilakukan secara sengaja dengan pertimbangan ketiga kedai kopi ini menjual kopi lokal dan kopi non lokal sehingga dapat dilihat preferensi konsumen dalam mengkonsumsi kopi di kota jambi.

Penarikan sample dilakukan dengan metode simpel random sampling. Jumlah penduduk 591.134 Jiwa (BPS,Kota Jambi dalam angka 2019). Penghitungan sampel dengan rumus Slovin

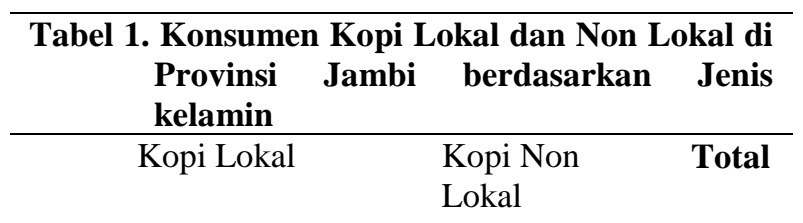

\begin{tabular}{lrrrrrr} 
JenisKelamin & Jml & $\%$ & Jml & $\%$ & & \\
Laki-laki & 60 & 60 & 20 & & 20 & \\
Perempuan & 10 & 10 & 10 & 10 & \\
$\begin{array}{l}\text { Total } \\
\text { Responden }\end{array}$ & $\mathbf{7 0}$ & & $\mathbf{3 0}$ & & $\mathbf{1 0 0}$ \\
\hline
\end{tabular}

$$
\begin{aligned}
& \mathrm{n}=\mathrm{N} /\left(1+\left(\mathrm{N} \mathrm{x} \mathrm{e}^{2}\right)\right) \mathrm{n}=\mathrm{N} / \mathrm{N} \cdot \mathrm{d}^{2}+1 \\
& \mathrm{n}=591.134 / 591.134 \mathrm{X} 0,0025+1 \\
& \mathrm{n}=591.134 /\left(1+\left(591.134 \times 0,1^{2}\right)\right) \\
& \mathrm{n}=591.134 /(1+(591.134 \times 0,01)) \\
& \mathrm{n}=591.134 / 5.912,34 \\
& \mathrm{n}=99,98 \\
& \mathrm{n}=100
\end{aligned}
$$

Data penelitian dianalisis deskriptif dan untuk melihat hubungan usia konsumen dan preferensi konsumen menggunakan metode korelasi Rank Spearman menggunakan program statistik SPSS. Dalam penelitian ini yang dimaksud Kopi Lokal adalah Kopi Kerinci, Kopi Muara Madras, dan Kopi Liberika Tungkal Komposit dalam bentuk serbuk kopi siap minum yang dikombinasikan dengan varian yang ada di kedali kopi. Sedangkan masyarakat Kota Jambi adalah konsumen kopi yang membeli kopi di Kota Jambi.

Adapun hipotesis dalam penelitian ini adalah terdapat hubungan anatara usia konsumen kopi dengan preferensi dalam mengkonsumsi kopi lokal

\section{HASIL PENELITIAN}

Penelitian ini dilakukan dengan mengambil sampel dari 3 kedai kopi yang terdapat di Kota Jambi yakni Hello Sapa, Camp Coffe, dan Kopi Juaro. Ketiga kedai kopi ini dipilih dengan pertimbangan tidak semua kedai kopi di Kota Jambi menjual Kopi Lokal. Setelah dilakukan survei awal diperoleh bahwa 3 kedai kopi ini menjual varian olahan kopi varietas lokal Jambi dan kopi non lokal yang varietasnya berasal dari luar Jambi. Pada tabel 1 terlihat bahwa dari total responden terdapat $70 \%$ responden

yang mengkonsumsi kopi lokal Jambi yakni 60 orang berjenis kelamin laki-laki dan 10 orang berjenis kelamin perempuan. Sedangkan $30 \%$ responden mengkonsumsi kopi non lokal yakni 20 orang berjenis kelamin laki-laki dan 10 orang berjenis kelamin perempuan.

Hasil penelitian juga menunjukkan bahwa persentase terbesar usia konsumen 
kopi adalah usia 18-21 tahun dan 22-25 tahun yakni sebanyak $42 \%$. Sedangkan persentase terkecil yakni responden usia 3437 tahun yakni sebanyak $0 \%$. Hal ini menunjukkan bahwa sebagian besar pengunjung kedai kopi dikota Jambi didominasi oleh anak muda yang berusia 1825 tahun. Hal ini dikarnakan anak-anak muda di Kota Jambi memiliki kecenderungan berkumpul dikedai kopi bersama teman - temannya.

Tabel 2. Usia Konsumen Kopi Lokal dan Non Lokal di Provinsi Jambi

\begin{tabular}{lcc}
\hline Usia (tahun) & Jumlah Orang & Persentase \\
\hline $18-21$ & 42 & 41,67 \\
$22-25$ & 42 & 41,67 \\
$26-29$ & 7 & 6,67 \\
$30-33$ & 3 & 3,33 \\
$34-37$ & 0 & 0,00 \\
$38-41$ & 3 & 3,33 \\
$42-45$ & 3 & 3,33 \\
Total & $\mathbf{1 0 0}$ & $\mathbf{1 0 0 , 0 0}$ \\
\hline
\end{tabular}

Hasil penelitian menunjukkan bahwa persentase terbesar pengunjung kedai kopi adalah pelajar dan mahasiswa yakni sebanyak $67 \%$ dari total 100 orang responden. Sementara persentase alin kecil yakni PNS/TNI/Polri dan Pegawai BUMN/BUMD yakni sebanyak $0 \%$ dari total 100 orang responden konsumen kopi dikedai kopi. Hal ini sejalan dengan hasil penelitian yang memperlihatkan usia mayoritas responden pengunjung kedai kopi yang berusia 18-25 tahun (tabel 2).

Selain itu, hasil penelitian ini juga menunjukkan bahwa $85 \%$ responden mengetahui manfaat mengkonsumsi kopi sebagaimana terlihat pada tabel 4 .
Tabel 3. Konsumen Kopi Lokaldan

Non Lokal di Provinsi

Jambi berdasarkan

Pekerjaan

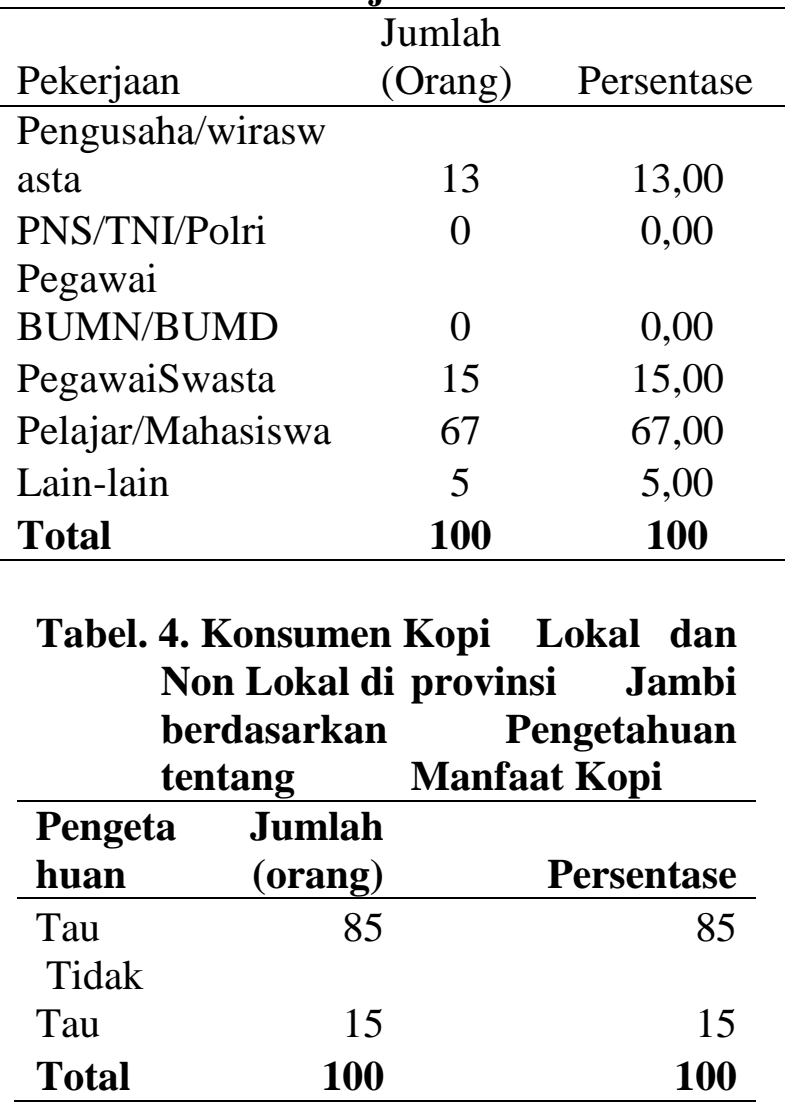

Tabel 5. Preferensi Konsumen Kopi di Kota Jambi

Jumlah

\begin{tabular}{lrc} 
Preferensi & (orang) & Persentase \\
\hline Kopi Lokal & 70 & 70 \\
Kopi Non & & \\
Lokal & 30 & 30 \\
Total & $\mathbf{1 0 0}$ & $\mathbf{1 0 0}$
\end{tabular}

$70 \%$ responden memilih untuk mengkonsumsi kopi lokal Jambi dibandingkan dengan kopi non lokal. Sedangkan $30 \%$ sisanya lebih memilih untuk mengkonsumsi kopi non lokal dengan berbagai alasan diantaranya ingin mencoba aneka rasa kopi dari berbagai daerah yang tersedia di kedai kopi tersebut dan ada juga yang lebih menyukai kopi non lokal karena menilai bahwa rasa kopi tersebut lebih enak. 
Selain itu, konsumen yang memilih untuk mengkonsumsi kopi lokal Jambi mengatakan bahwa menyukai rasa khas kopi lokal Jambi terutama varietas yang berasal dari Kopi kerinci.

Tabel 6. Alasan Mengkonsumsi Kopi Konsumen Kopi di Provinsi Jambi

\begin{tabular}{lcr}
\hline Alasan & $\begin{array}{r}\text { Jumlah } \\
\text { (orang) }\end{array}$ & Persentase \\
\hline Menghilangkan Kantuk & 20 & 20,00 \\
Teman merokok & 5 & 5,00 \\
untuk stamina/daya & & \\
tahan tubuh & 11 & 11,00 \\
Relaks & 7 & 7,00 \\
Enak/Nikmat & 30 & 30,00 \\
Teman mengobrol & 7 & 7,00 \\
Kebutuhan & 8 & 8,00 \\
meningkatkan mood & 12 & 12,00 \\
Total & $\mathbf{1 0 0}$ & $\mathbf{1 0 0}$ \\
\hline
\end{tabular}

$\begin{array}{cccc}\text { Dari tabel } 6 & \text { kita dapat melihat } \\ \text { berbagai } & \text { alasan } & \text { konsumen }\end{array}$ mengkonsumsi kopi. Persentase terbesar yakni $30 \%$ konsumen mengkonsumsi kopi karena kopi punya cita rasa yang enak dan nikmat. Sedangkan persentase terkecil yakni $5 \%$ konsumen kopi mengkonsumsi kopi karena minuman kopi cocok untuk dijadikan minuman ketika mereka sedang merokok dimana mereka menyebut dengan istilah kopi teman rokok.

\section{Hubungan antara jenis kelamin dengan preferensi konsumen}

Hasil analisis Spss menggunakan uji rank spearman diperoleh nilai Correlation coefficient -0,151 dimana angka ini menunjukkan hubungan sangat lemah antara usia konsumen kopi dengan preferensi konsumsi kopi, koefisien juga bertanda negatif yang menunjukkan hubungan tidak searah antara usia konsumen dengan preferensi konsumen kopi. Hasil analisis juga menunjukkan nilai signifikan Sig. (2tailed) 0,134 yang menunjukkan bahwa hubungan antara usia konsumen dengan preferensi dalam mengkonsumsi kopi tidak signifikan.

\section{Correlations}

\begin{tabular}{|lll|r|r|}
\hline & & \multicolumn{1}{c|}{ usia } & \multicolumn{1}{|c|}{ preference } \\
\hline & & Correlation & 1,000 &,- 151 \\
& Usia & Coefficient & &, 134 \\
Spearman's & & Sig. (2-tailed) & $\cdot$ & 100 \\
rho & $\mathrm{N}$ & 100 & 1,000 \\
& & Correlation &,- 151 & \\
& preference & Coefficient &, 134 & 100 \\
& & Sig. (2-tailed) & 100 & \\
& & $\mathrm{~N}$ & & \\
\hline
\end{tabular}




\section{KESIMPULAN}

1. Mayoritas konsumen kopi memilih kopi lokal dibandingkan kopi non lokal.

2. Hubungan usia konsumen dengan prefernsi konsumsi kopi adalah tidak signifikan.

\section{DAFTAR PUSTAKA}

Kotler, P. (2000). ManajemenPemasaran, Prehalindo, Jakarta.

Kotler, P. (2017). Mengenal Kopi dan Anggota Keluarganya. Kopikini.com. diakses 13 Februari 2020

Kotler, P. (2020). Tanaman Kopi. Perkebunan.litbang.pertanian.go.id

Naibaho, T. (2016). Analisis Preferensi Konsumen Terhadap Kopi Lokal Sumatera Di Kota Medan. Program Studi Magister Agribisnis Fakultas Pertanian Universitas Sumatera Utara Medan. repositori.usu.ac.id.

Naibaho, T. (2019). Pembangunan Perkebunan Provinsi Jambi Tahun 2019. Dinas Perkebunan Provinsi Jambi.

Rianto, N. (2010).TeoriMikroekonomi, Jakarta:Kencana,.

Yunita, E. (2016). Analisis Faktor yang Mempengaruhi Preferensi Konsumen (Kasus Ozaizy Coffee n' Resto, Kota Bogor). Departemen Agribisnis Fakultas Ekonomi Dan Manajemen, Institut Pertanian Bogor.

Zulfi, J. (2017). Analisis Preferensi Konsumen Terhadap Pembelian Kopi Instan White Coffee Di Kecamatan Kebumen Kabupaten Kebumen. Fakultas Pertanian, Universitas Sebelas Maret. 